Proceedings of XIX International Scientific Conference "New Technologies and Achievements in Metallurgy, Material Engineering, Production Engineering and Physics", Częstochowa, Poland, June 7-8, 2018

\title{
The Influence of Thickness and Number of Layers on Selected Properties of $\mathrm{Cu} / \mathrm{Ni}$ Systems
}

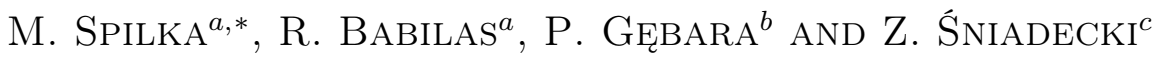 \\ ${ }^{a}$ Silesian University of Technology, Faculty of Mechanical Engineering, \\ Institute of Engineering Materials and Biomaterials, S. Konarskiego 18a, 44-100 Gliwice, Poland \\ ${ }^{b}$ Częstochowa University of Technology, Faculty of Production Engineering and Materials Technology, \\ Institute of Physics, al. Armii Krajowej 19, 42-200 Częstochowa, Poland \\ ${ }^{c}$ Polish Academy of Sciences, Institute of Molecular Physics, Department of Magnetic Alloys, \\ M. Smoluchowskiego 17, 60-179 Poznań, Poland
}

\begin{abstract}
The increasing demand for thin-layer materials influences on development of their production technologies and a range of potential applications. The properties of these materials (e.g. physical properties) can find new applications and solve existing limitations. Multi- and thin-layer metal systems are a special group of materials which can be successfully used for suppression of electromagnetic waves. Properly designed multilayer systems can exhibit the effect of a giant magnetoresistance. The research results include morphology observations and study of surface topography of $\mathrm{Cu} / \mathrm{Ni}$ multilayer systems with nanometric layers. The layers were electrolytically produced on a thin copper foil substrate. The investigations of the physical properties of the systems have shown that quantity and thickness of the layers in the multilayer system have an effect on magnetic properties. The obtained layers are characterized by good quality. Moreover, they are compact and homogeneous. The topographical studies have not detected major surface defects of multilayer systems.
\end{abstract}

DOI: 10.12693/APhysPolA.135.172

PACS/topics: 81.15.Pq, 75.70.Cn, 75.47.De, 68.37.Hk, 68.37.Ps

\section{Introduction}

Metallic multilayer systems and their properties have become in modern engineering an interesting research topic in recent years because of their promising technological applications and fundamental scientific importance [1]. These multi- and thin-layer metal systems possess interesting magnetic, electrical, optical, and mechanical properties [2]. Desirable properties of multilayers systems mainly depend on the component materials, processing conditions, microstructure, and interfacial structure $[3,4]$.

The idea of using multilayer systems is based on the fact that conductive layers (e.g. copper, silver) and layers of ferromagnetic (e.g. nickel, iron, cobalt) with microand nanometric thicknesses and different structure are alternately arranged.

Among many multilayers systems with differential constituent composition, the $\mathrm{Cu} / \mathrm{Ni}$ systems have exhibited a great deal of attentions due to identical crystallographic structure (fcc) of copper and nickel, very small lattice misfit (2.5\%) of both elements and excellent properties [1-3].

Multilayers composed of $\mathrm{Cu}$ and $\mathrm{Ni}$ are interesting by the gigantic magnetoresistance (GMR) effect which is characteristic for thin-layered ferromagnetic/

*corresponding author; e-mail: monika.spilka@polsl.pl non-magnetic material systems [5]. Due to these specific properties, they have been applied in electronics and in information recording and readouting devices $[2,6]$.

$\mathrm{Cu} / \mathrm{Ni}$ multilayers are also easy to produce using many methods including electrodeposition and vacuum techniques, especially sputtering or molecular beam epitaxy. However, metallic multilayer systems obtained by means of different methods do not always show the same structural and magnetic properties $[7,8]$.

Electrodeposition is successfully used to deposit multiand thin-layer metal systems. Furthermore, electrodeposition also offers a number of advantages such as rapid deposition at room temperature and pressure and low cost. In electrodeposition, the parameters of this process have influence on the layers thickness and changes of many properties of fabricated multilayers [9-11].

The paper presents the results of physical properties investigations of $\mathrm{Cu} / \mathrm{Ni}$ multilayer systems fabricated by electrolysis process, as well as the observation of surface morphology, topography, and surface roughness analysis.

\section{Experimental procedure}

$\mathrm{Cu} / \mathrm{Ni}$ multilayer systems, with variable layer thicknesses, were produced by electrolytic deposition. The substrate for research was a copper foil with dimensions of $50 \times 50 \mathrm{~mm}$ and $70 \mu \mathrm{m}$ of thickness, which was suitably cleaned. $\mathrm{Cu}$ and $\mathrm{Ni}$ alternate layers with quantity of $15,25,30$, and 45 were applied and the thickness of a single layer was $12 \mathrm{~nm}$ and $25 \mathrm{~nm}$. The copper layers 
were deposited from a cyanide bath with current density of $0.025 \mathrm{~A} / \mathrm{dm}^{2}$. The application time of copper layers was 79 and $165 \mathrm{~s}$, respectively. Nickel plating process occurred from the Watts bath at $50^{\circ} \mathrm{C}$, the current density was $0.2 \mathrm{~A} / \mathrm{dm}^{2}$. Time of applying nickel layers was respectively 30 and $62.5 \mathrm{~s}$.

The test of magnetic properties was carried out in a vibrating sample magnetometer. The analysis was conducted within the range of magnetic field of $-2000 \mathrm{kA} / \mathrm{m} \div 2000 \mathrm{kA} / \mathrm{m}$. This measurement was additionally concentrated within the range of $-1600 \mathrm{kA} / \mathrm{m}$ $\div 1600 \mathrm{kA} / \mathrm{m}$.

The study of giant magnetoresistance effect was performed on the physical property measurement system (PPMS) of Quantum Design. The measurements were performed using a four-point probe at $300 \mathrm{~K}$ for magnetic field strength in the range of $-3 \mathrm{~T}$ to $3 \mathrm{~T}$ and at a temperature of $100 \mathrm{~K}$ for the magnetic field strength of $0 \mathrm{~T}$ and $1 \mathrm{~T}$. The study was conducted for a magnetic field set along the direction of current flow (longitudinal magnetoresistance - LMR). The research involved four multilayer systems, whose parameters are summarized in Table I.

TABLE I

Parameters of multilayer system samples and distance of voltage contacts.

\begin{tabular}{c|c|c|c}
\hline \hline Sample & $\begin{array}{c}\text { Sample } \\
\text { thickness } \\
{[\mu \mathrm{m}]}\end{array}$ & $\begin{array}{c}\text { Width of } \\
\text { the sample } \\
{[\mathrm{mm}]}\end{array}$ & $\begin{array}{c}\text { Distance of } \\
\text { voltage } \\
\text { contacts } \\
{[\mathrm{mm}]}\end{array}$ \\
\hline $\mathrm{Cu} / \mathrm{Ni} \times 15(25 \mathrm{~nm})$ & 61.50 & 4.72 & 1.96 \\
$\mathrm{Cu} / \mathrm{Ni} \times 25(25 \mathrm{~nm})$ & 62.50 & 5.46 & 2.48 \\
$\mathrm{Cu} / \mathrm{Ni} \times 15(12 \mathrm{~nm})$ & 60.72 & 3.66 & 2.38 \\
$\mathrm{Cu} / \mathrm{Ni} \times 30(12 \mathrm{~nm})$ & 61.44 & 4.02 & 3.62
\end{tabular}

The surface morphology of the obtained multilayers was observed by using the Zeiss SUPRA 25 scanning electron microscope equipped with the EDS chemical analysis system.

Examination of topography of the samples and roughness measurement were performed using the Park Systems AFM XE-100 atomic force microscope in noncontact mode. The results of the studies were analysed using the XEI software.

\section{Results and discussion}

On a basis of obtained graphs of the relationship between magnetic moments and the magnetic field (magnetic hysteresis loop), $\mathrm{Ni} / \mathrm{Cu}$ multilayer systems can be described as a soft magnetic material due to narrow shape of the hysteresis loop (Fig. 1). Depending on number of applied layers, as well as their thickness, the magnetic moment $(M)$ was changed. This indicates that both amount and thickness of layers constituting the multilayer system have an effect on magnetic properties.

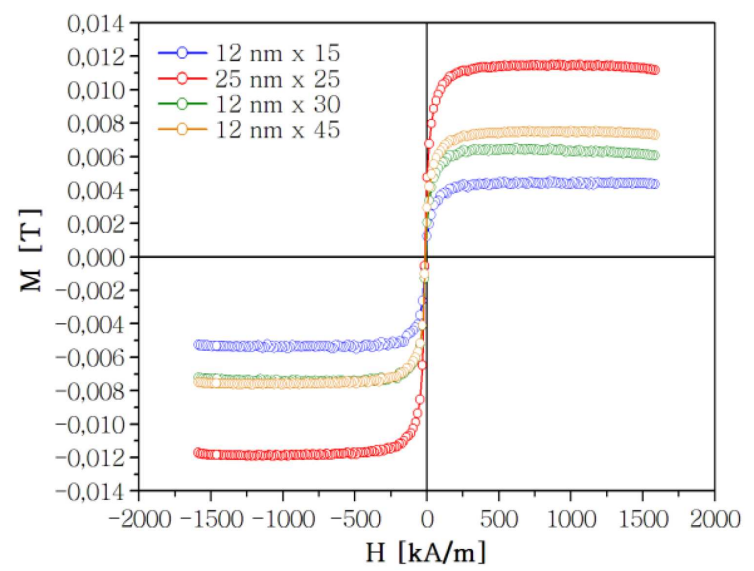

Fig. 1. The hysteresis loops of the $\mathrm{Cu} / \mathrm{Ni}$ system, a single layer thickness is $12 \mathrm{~nm}$ and $25 \mathrm{~nm}$.

With the increase of layer thickness from $12 \mathrm{~nm}$ to $25 \mathrm{~nm}$, the magnetic moment increases from $0.005 \mathrm{~T}$ to $0.012 \mathrm{~T}$.

Examples of magnetic hysteresis loops for $\mathrm{Cu} / \mathrm{Ni}$ multilayers obtained by means of electrochemical deposition, published in $[7,9]$ also showed the changes in the magnetic properties. They might arise from the change in the $\mathrm{Ni}$ and $\mathrm{Cu}$ content of the samples caused by the variation of $\mathrm{Cu}$ layer thicknesses.

All imperfections of multilayer structure (e.g., roughness of interlayer boundary between ferromagnetic and non-magnetic layers) have large impact on magnetic properties of multilayer metallic systems [7].

In studies carried out at the station for measuring of giant magnetoresistance effect, this phenomenon was not detected in full range of magnetic fields. Many factors may significantly influence on GMR of electrodeposited multilayer (e.g. electrolyte purity, electrolyte $\mathrm{pH}$, thickness of $\mathrm{Cu}$ and Ni layers, roughness). According to literature the GMR effects depends on the overall thickness of multilayer system. Giant magnetoresistance of multilayers enhances strongly with increase the number of bilayers [12]. Also magnetic and non-magnetic layer thickness have an influence on GMR. The GMR magnitude reaches a maximum value for the $\mathrm{Cu}$ layer thickness of $1.5 \mathrm{~nm}$ and for larger $\mathrm{Cu}$ layer thickness it decreases with increasing $\mathrm{Cu}$ layer thickness [9]. The multilayer with the very thin magnetic layer displays lower GMR. When the magnetic layer thickness increases, the GMR values also increases since the layer thickness reach to optimum value. Further increase in magnetic layer thickness (as high as $10 \mathrm{~nm}$ or more), leads to reduction of the GMR values. Some references report that in the case of electrochemically deposited multilayer $\mathrm{Cu} / \mathrm{Ni}$ systems $\mathrm{GMR}$ effect was barely $1-1.5 \%$ [7, 9]. Tokarz et al. [13] presented that the GMR value of $\mathrm{Cu} / \mathrm{Ni}$ multilayer system is $2.5 \%$ with current flowing in plane of the multilayer and the applied magnetic field was 0 to $1.5 \mathrm{~T}$ at $50 \mathrm{~K}$. The maximum of $7 \%$ GMR was achieved when the total number of bilayer was $6000[12]$. 


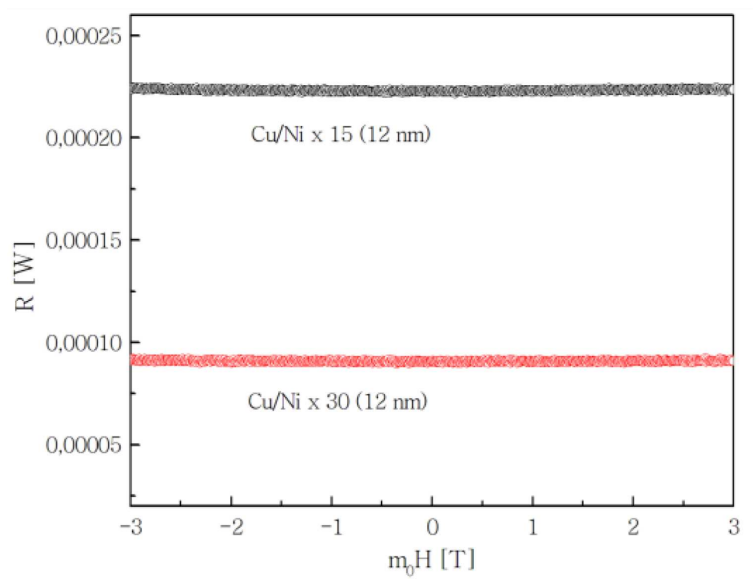

Fig. 2. Dependence of resistance on magnetic field for $\mathrm{Cu} / \mathrm{Ni}$ systems; test carried out at $100 \mathrm{~K}$.

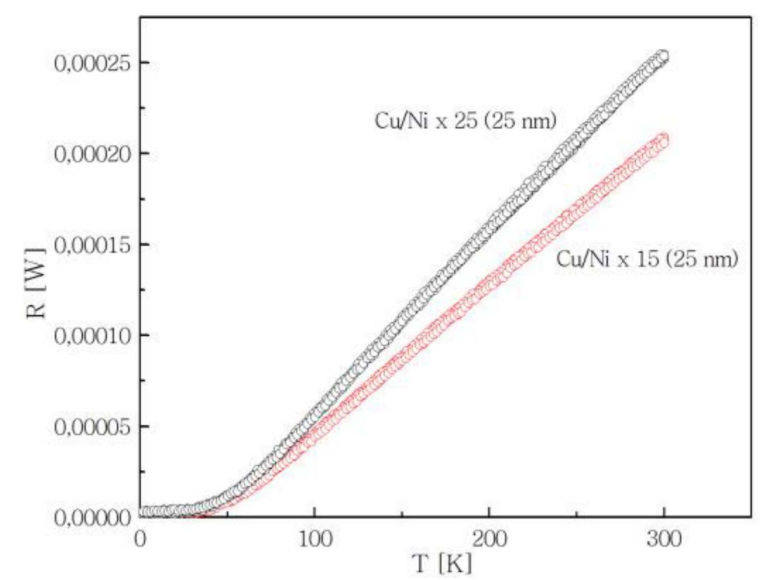

Fig. 3. Changes of resistance in a function of temperature for $\mathrm{Cu} / \mathrm{Ni}$ systems.

Regardless of magnetic field, the resistance of multilayer systems is kept constant (Fig. 2).

Resistance tests of $\mathrm{Cu} / \mathrm{Ni}$ systems were also performed at a reduced temperature in magnetic field of $0 \mathrm{~T}$ and $1 \mathrm{~T}$ (Fig. 3). The increase of resistance in a function of temperature can be noticed. It is linear in the range of $50 \div 300 \mathrm{~K}$. Changes of resistance without a magnetic field are minimal. Plots for $\mathrm{Cu} / \mathrm{Ni} \times 30(12 \mathrm{~nm})$ system show artifacts (Fig. 4), which were probably related to changes of electrical contacts of the four-point probe during sample cooling. They probably may come from the resulting stresses.

The microscopic images of the surface layer of $\mathrm{Cu} / \mathrm{Ni}$ multilayer system together with the analysis of the chemical composition are shown in Fig. 5a,b. The obtained layers in electrolysis process are continuous and compact. Visible copper structure is homogeneous with a strong development of nucleation sites (in the case of layers of smaller thickness). Extending deposition time of layers resulted in an uniform layer growth in a form of spheroidal structures.

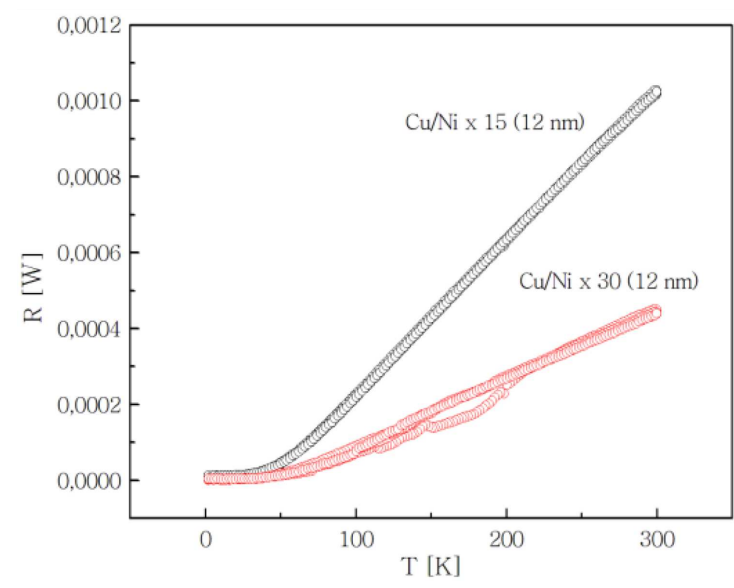

Fig. 4. Changes of resistance in a function of temperature for $\mathrm{Cu} / \mathrm{Ni}$ systems.
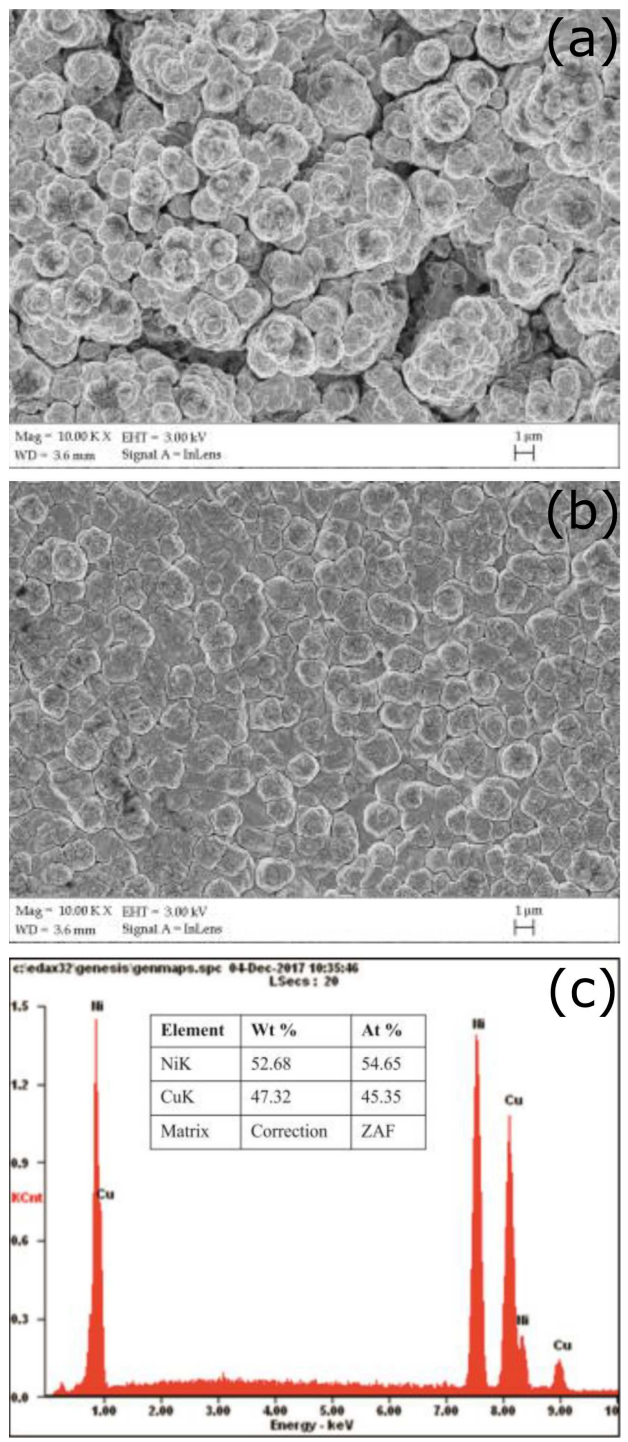

Fig. 5. SEM images of $\mathrm{Cu}$ layer in $\mathrm{Cu} / \mathrm{Ni}$ system, a single layer thickness is (a) $12 \mathrm{~nm}$, (b) $25 \mathrm{~nm}, 10,000 \times$, (c) EDS analysis. 
Also Sahin et al. [14] obtained cauliflowers-like granules structure, whose size becomes smaller with increase of $\mathrm{Cu}$ contents in the multilayers.

The EDS microanalysis showed the presence of both copper and nickel elements (Fig. 5c). The results come from the surface and deeper layers of the sample.

Images of the surface topography which define the surface morphology were made for selected area of the sample $(5 \times 5 \mu \mathrm{m})$ with the $\mathrm{Cu} / \mathrm{Ni}$ system and copper foil as the substrate (Fig. 6).
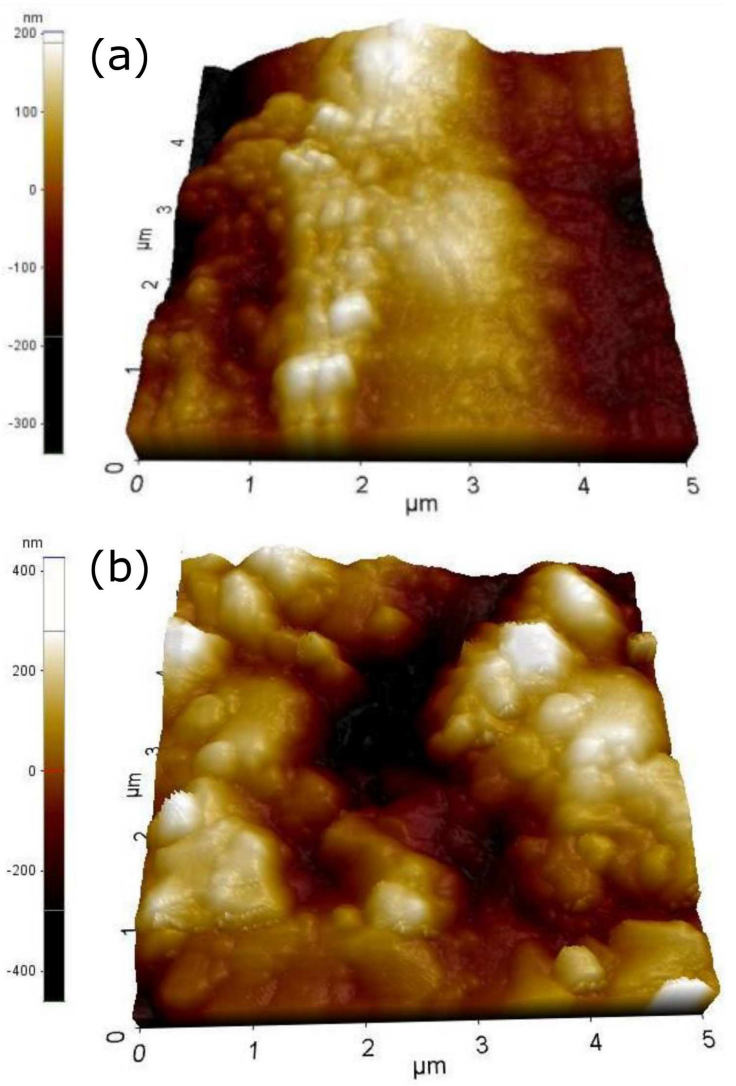

Fig. 6. The AFM images of three-dimensional visualization of topography of sample surface (copper foil) (a), the $\mathrm{Cu} / \mathrm{Ni}$ system about $12 \mathrm{~nm}$ of single layer thickness (b).

TABLE II

The roughness parameters of $\mathrm{Cu} / \mathrm{Ni}$ systems and the substrate material

\begin{tabular}{l|c|c|c}
\hline \hline \multicolumn{1}{c|}{ Sample } & Ra $[\mathrm{nm}]$ & RMS [nm] & Max. [nm] \\
\hline substrate material & 77.57 & 96.02 & 202.72 \\
$\mathrm{Cu} / \mathrm{Ni}(12 \mathrm{~nm})$ & 111.85 & 141.96 & 426.62 \\
$\mathrm{Cu} / \mathrm{Ni}(25 \mathrm{~nm})$ & 125.62 & 155.78 & 411.59
\end{tabular}

Based on results of tests, roughness parameters: mean roughness (roughness average - Ra), root mean square (RMS), and maximum profile height (Max.) for $\mathrm{Cu} / \mathrm{Ni}$ systems and substrate material were determined (Table II).
It was found that the surface roughness increases exponentially with increase of total thickness of multilayer systems. If the $\mathrm{Cu}$ layer is thicker, the surface roughness is greater.

\section{Conclusions}

The fabrication of thin layers by electrochemical method has many advantages. However, there are some problems hindering the use of electroplating technology of nanometric thickness layers. One of them is a lack of repeatability.

Conducted surface tests by using EDS analysis confirmed the deposition of copper and nickel layers. The number of deposited layers and their thickness have a direct influence on the magnetic properties of the multilayer systems produced.

Based on a shape of the hysteresis loops it can be concluded that the obtained multilayer $\mathrm{Cu} / \mathrm{Ni}$ systems are magnetically soft ferromagnetic (coercivity value is $c a$. $6.44 \mathrm{kA} / \mathrm{m})$.

Investigations of manufactured multilayer systems did not show the occurrence of the giant magnetoresistance effect regardless of thickness and number of applied layers. Plots of resistance in a function of magnetic field strength are linear over entire range of magnetic fields used, in the range of $-3 \mathrm{~T}$ to $3 \mathrm{~T}$. This situation is caused by high layer thickness in the tested samples.

Layers with a thickness of 12 and $25 \mathrm{~nm}$ do not allow an occurrence of the giant magnetoresistance effect. Theirs thickness is higher than the average path of a free electron in metal materials (about $10 \mathrm{~nm}$ ). Therefore, a condition necessary for an occurrence of the GMR effect is a passage of an electron through two, opposite magnetized ferromagnetic layers are not met [10].

Changes of resistance in a function of temperature show a linear relationship. The positive temperature coefficient of resistance of $\mathrm{Cu} / \mathrm{Ni}$ multilayer systems was confirmed.

To sum up, it has been found that the electrochemical process allows to obtain good quality layers, characterized by a continuous and compact structure with irregularities similar to those occurring on the substrate.

\section{References}

[1] T. Fu, X. Peng, X. Chen, S. Weng, N. Hu, Q. Li, Z. Wang, Sci. Rep. 6, 35665 (2016).

[2] B. Kucharska, E. Kulej, A. Wróbel, Opt. Appl. XLII, 4 (2012).

[3] H.C. Barshilia, K.S. Rajam, Surf. Coat. Technol. 155, 195 (2002).

[4] M. Spilka, A. Kania, R. Nowosielski, A. Maciej, Metalurgija 56, 3 (2017).

[5] B. Kucharska, E. Kulej, Archiv. Metall. Mater. 55, 1 (2010).

[6] B. Kucharska, E. Kulej, M. Gwoździk, Archiv. Metall. Mater. 57, 3 (2012). 
[7] M. Duś-Sitek, M. Nabiałek, B. Gągorowska, Mater. Opt. Appl. XXXIX, 4 (2009).

[8] Q. Zhou, J.Y. Xie, F. Wang, P. Huang, K.W. Xu, T.J. Lu, Acta Mech. Sin. 31, 3 (2015).

[9] H. Kuru, H. Kockar, M. Alper, J. Supercond. Nov. Magn. 26, 779 (2013).

[10] M. Jafari Fesharaki, S. Manouchehri, Z. Sadeghi, M.H. Yousefi, R. Jalajerdi, J. Nano. Struct. 5, 3 (2015).
[11] Y. Rheem, Kor. J. Mater. Res. 20, 2 (2010).

[12] N. Rajasekaran, S. Mohan, Crit. Rev. Solid State Mater. Sci. 37, 158 (2012).

[13] A. Tokarz, A. Wolkenberg, A. Przeslawski, J. Electrochem. Soc. 149, 11 (2002).

[14] T. Sahin, H. Kockar, M. Alper, J. Magn. Magn. Mater. 373, 128 (2015). 